\title{
The Effect of Various Milling Time Duration On The Characteristic of Glass Ionomer Cement (GIC) with The Addition of Liquid Pmve-Ma
}

\author{
Djony Izak Rudyardjo ${ }^{1, a)}$, Jan Ady ${ }^{1}$, and Aditya Budi Fauzi ${ }^{1}$ \\ ${ }^{1}$ Departement of Physics, Faculty of Science and Technology, Universitas Airlangga \\ a) Corresponding author: adityabfauzi-11@fst.unair.ac.id
}

\begin{abstract}
A study entitled The Effect of Milling Time Duration on the Characteristics of Glass Ionomer Cement (GIC) Dental Cement with the Addition of Liquid PMVE-MA aims to determine the effect of milling time duration on the physical and mechanical properties of Glass Ionomer Cement, and to determine the optimum milling time duration in order to obtain GIC dental cement with the best characteristic to be applied as a dental restoration material. The duration of the milling time was 80 minutes, 90 minutes, 100 minutes, and 110 minutes. After the milling process, the next process was sintered at a temperature of $1200^{\circ} \mathrm{C}$ for 1 hour to form Powder Glass Ionomer. Then Powder Glass Ionomer was added with Poly Methyl Vinyl EtherMaleic Acid (PMVE-MA) to form a paste. The mixed paste was then formed. Sample characterization was the density test, the compressive strength test, and the vickers hardness test. The results of the density test obtained the highest value of 1.683 gram $/ \mathrm{cm}^{3}$, the compressive strength test of $71.841 \mathrm{MPa}$, and the highest value of the hardness test of $92.3 \mathrm{Kg} / \mathrm{mm}^{2}$. These results increased as the increasing milling time duration up to 110 minutes.
\end{abstract}

\section{INTRODUCTION}

Currently, dental caries cases in Indonesia are increasing. Dental caries cases are caused by several factors, such as accidents and cavities. In line with The Basic Health Research, there are around 72.1\% of Indonesia's population who have experienced cavities and $46.5 \%$ of them are active caries that have not been treated. Based on Basic Health Research (Riskesdas, 2007), The National prevalence for oral and dental problems is $25.9 \%$, as many as 14 provinces have a prevalence of oral and dental problems above the national figures.

Tooth restoration or dental filling is one solution to overcome tooth decay caused by caries. Tooth restoration can be performed by using materials such as dental cement. This prevention is carried out in order to restore the shape of the teeth to normal. In addition, to prevent the development of decay-causing bacteria on the teeth, thus the teeth can function properly.

There are four types of dental cement commonly used in dentistry, namely zinc oxide and eugenol cement (zinc oxide and eugenol cement), polycarboxylate cement (polycarboxylate cement), zinc phosphate cement (zinc phosphate cement), and glass ionomer cement). Each of these dental cements has different properties and characteristics.

Glass Ionomer Cement (GIC) is a dental filling material that is widely used by dentists due to its many advantages. GIC consists of two main components, namely Ionomer Glass Powder and liquid Poly Methyl Vinyl Ether-Malaic Anhydride (PVME-MA). The powders used are silica $\left(\mathrm{SiO}_{2}\right)$, alumina $\left(\mathrm{Al}_{2} \mathrm{O}_{3}\right)$, calcium fluoride $\left(\mathrm{CaF}_{2}\right)$, and aluminum phosphate $\left(\mathrm{AlPO}_{4}\right)$. Silica acts as the main framework for the oxide network in developing a bond between the glass and the tissue by making a side deposit of calcium. Alumina plays a role in improving the mechanical properties of GIC, which affects the level of hardness. Calcium fluoride acts as an antibacterial to inhibit the spread of bacteria due to caries in teeth. Meanwhile, aluminum phosphate plays a role in increasing tooth strength (Widana,2012).

The main properties of GIC are its ability to adhere to enamel or dentin without significant shrinkage or heat, have biocompatibility properties, there is a release of fluorides which react as anti-microbial and cariostatic (Palma,et al. 2002). The disadvantage of GIC when compared to other restorative materials is its brittle, thus the mechanical properties of GIC are relatively deficient (Sakaguchi,et al. 2012).

The variation of milling time duration in this study was expected to be able to improve the characteristics of GIC to be better than previous studies. The nature of GIC could be determined by the mixing process of its basic ingredients. The process included a homogeneity of the mixture of materials which gave uniform mechanical properties to the resulting GIC. Acquiring a homogeneous mixture, the milling process could be performed, while the milling time affected the yield 
of GIC.

In Anita's study (Anita. 2015) showed the effect of variations in the duration of milling time on the manufacture of dental cement for GIC. The variation of milling time duration used were $0,20,40,60$, and 80 minutes. From this research, it was found that the best milling time was 80 minutes because these results had the least number of pores and the smallest pore size. However, in this study the results of the density test and compressive strength test still did not meet the standards of GIC quality.

Therefore GIC was synthesized with variations in the duration of milling time of $80,90,100$, and 110 minutes with the composition of GIC used were $\mathrm{SiO} 241 \%, \mathrm{CaF} 221 \%$, Al2O3 27\%, and AlPO4 11\%, in accordance with the composition range from GIC and addition of liquid PVME-MA. It was expected to be able to increase the density and compressive strength of the GIC. The effect of variations in the duration of the milling time on the characterization of the GIC dental cement samples formed could be seen through several tests. Some of these tests included the physical properties test which was obtained by the density test, and the mechanical properties test which was determined by the compressive strength test and the Vickers hardness test.

\section{EXPERIMENTAL METHOD}

\section{Preparation}

The initial step in this study was to prepare the equipment and materials and determine the composition of the materials needed to manufacture dental cement for GIC. The tools used are analytical balance, HEM (High Energy Milling), spatula cement, pipette, furnace, mixing slab, acrylic molding, load for samples, calipers, plastic filling instruments, plugger cement, mortar, petri dishes, crucibles, Micro Vickers. Hardness, and the Shimadzu AG-10 TE Autograph.

The functions of each tool included an analytical balance to weigh the powder, HEM was used to mix silica powder, calcium fluoride powder, alumina, and aluminum phosphate until it is homogeneous. The cement spatula was used to stir the material from the milling process, the pipette was used to take PMVE-MA liquid, the furnace was used for heating (sintering), the crucible was used as a place for the sintering process, the mixing slab was used to mix the Glass Ionomer Cement powder with PMVE-MA liquid, acrylic molds were used to form dental cement, plastic filling instruments were used to add dental cement samples into the molds, and calipers were used to measure the diameter of the samples.

The materials used were silica powder $\left(\mathrm{SiO}_{2}\right)$, calcium fluoride powder $\left(\mathrm{CaF}_{2}\right)$, alumina powder $\left(\mathrm{Al}_{2} \mathrm{O}_{3}\right)$, aluminum phosphate powder $\left(\mathrm{AlPO}_{4}\right)$, and PMVE-MA liquid.

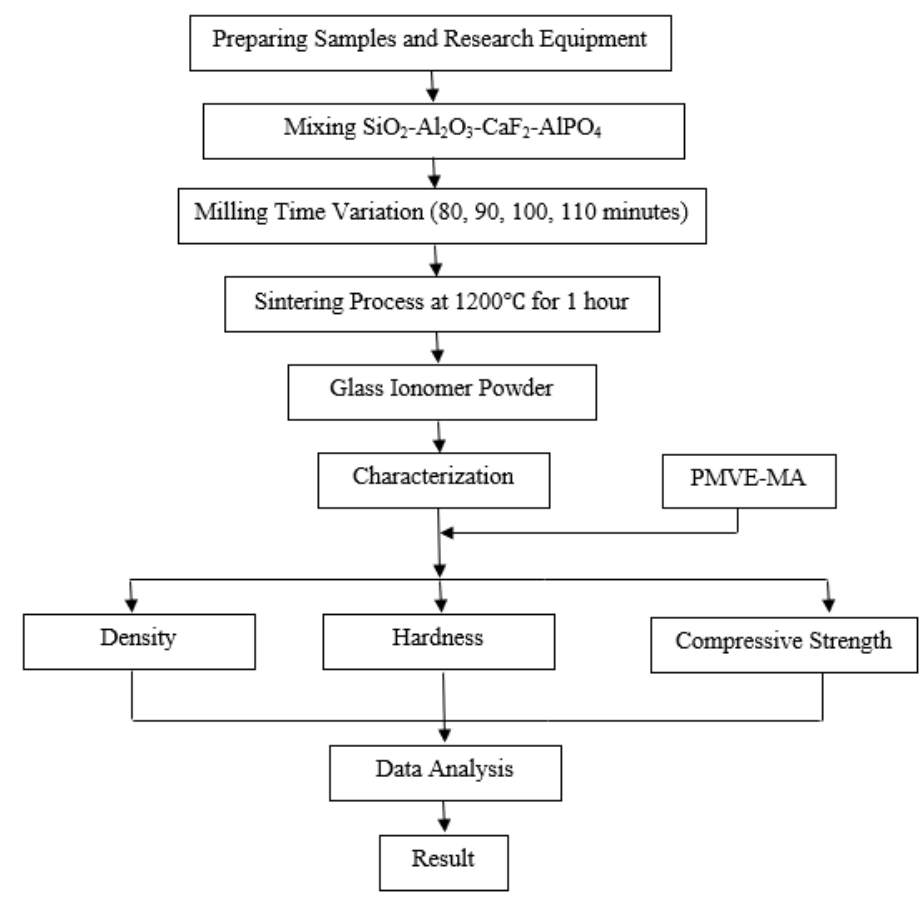

FIGURE 1. Flowchart of Research

\section{Manufacturing Samples}

The synthesis process of Glass Ionomer Cement (GIC) had several stages. The first stage was the synthesis process of Glass Ionomer powder. Glass Ionomer powder was made by mixing powdered silica, alumina, calcium fluoride and aluminum phosphate using HEM, thus the mixture of ingredients became homogeneous. The weight percentages used in 
each powder included $41 \% \mathrm{SiO}_{2}, 27 \% \mathrm{Al}_{2} \mathrm{O}_{3}, 21 \% \mathrm{CaF}_{2}$, and $11 \% \mathrm{AlPO}_{4}$. While the variation in the duration of the milling time was shown in Table 1.

TABLE 1. Variation of Milling Time Duration for Glass Ionomer Cement Synthesis

\begin{tabular}{cccc}
\hline No. & Samples & $\begin{array}{c}\text { Weight Percentage (\%) SiO2 : } \\
\text { CaF2 }: \text { Al2O3 }: \text { AlPO4 }\end{array}$ & $\begin{array}{c}\text { Milling time } \\
\text { (minutes) }\end{array}$ \\
\hline 1 & A & $41: 21: 27: 11$ & 80 \\
\hline 2 & B & $41: 21: 27: 11$ & 90 \\
\hline 3 & C & $41: 21: 27: 11$ & 100 \\
\hline 4 & D & $41: 21: 27: 11$ & 110 \\
\hline
\end{tabular}

The second stage was the heating or sintering process at a temperature of $1200^{\circ} \mathrm{C} \mathrm{C}$ using a furnace (Ramarajavu, 2014). This sintering treatment intended to bind powdered grains to dental cement samples and reduced porosity at high temperatures. After the powder mixture was sintered, a Glass Ionomer powder would be formed.

The third stage was the addition of PMVE-MA liquid to the Glass Ionomer powder with a weight of 0.5 ml (7-8 drops) and 1.5 grams, respectively. Mixing the powder with PMVE-MA liquid manually using a cement spatula placed on the mixing slab glass. This mixing was done in stages in order to obtain a homogeneous mixture. Then putting the sample into the acrylic mold until the surface was flat. The dental cement mold was in accordance with the standard size of the sample to be tested for physical and mechanical properties. The molded sample was then dried at room temperature until it was a hard solid then the sample was ready for density test, hardness test, and compressive strength test.

\section{Samples Characterization}

Characterization was carried out to determine the physical properties, mechanical properties, and microstructure that emerged from the synthesis of Glass Ionomer Cement. Several tests were carried out to determine physical and mechanical properties, namely density test, compressive strength test, and hardness test.

Density Test

The density test was done to determine the density level of a composition in sample. The equipment used to determine the value of the volume and mass of the sample were the caliper and a digital balance that had accuracy of 0.01 grams. Measurements were made by weighing the Glass Ionomer Cement dental cement sample and then measuring the volume.

\section{Compressive Strength Test}

The compressive strength test was a measure of the force required to break the material. The compressive test procedure on the sample was executed by measuring and recording the length, width and height of the sample. Then putting the sample on the surface of the pressure testing machine and make sure the sample was straight and right in the middle of the loading area. Next, before turning on the pressure test instrument, adjust the surface of the pressing device on the machine hence it was in contact with the test surface of the sample. The compressive strength test was ready to be performed by applying a compressive load to the test material, thus it would deform until it broke. The value of compressive strength $(\sigma)$ was obtained from the ratio between the force $(F)$ and the compressive area $(A)$ using

$$
\text { the following equation: } \quad \sigma=\frac{F}{A}
$$

\section{Hardness Test}

Hardness test was the ability of a material to receive hard object pressure. The equipment used was the Vickers Hardness Test, where the material's resistance to a diamond indenter had a pyramid shape with a slope angle of $136^{\circ}$. The test were the value of the load used $(F)$ and the average of diagonal length $(\mathrm{d})$. From these values, the Vickers or VHN hardness value could be calculated using the following equation :

$$
V H N=\frac{1,854 x F}{d^{2}}=\frac{1,854 x F}{\left(\frac{d_{1}+d_{2}}{2}\right)^{2}}
$$




\section{RESULTS AND DISCUSSIONS}

\section{Density Test Result}

The density test intended to determine the density level of the Glass Ionomer Cement (GIC) dental cement sample which occured due to the influence of variations in milling time. The density test was performed by weighing the sample to determine the mass of the sample and calculating the sample volume. The density value could be calculated using the ratio between the mass and the volume of the sample. The results of the density value test was represented in Figure 2.

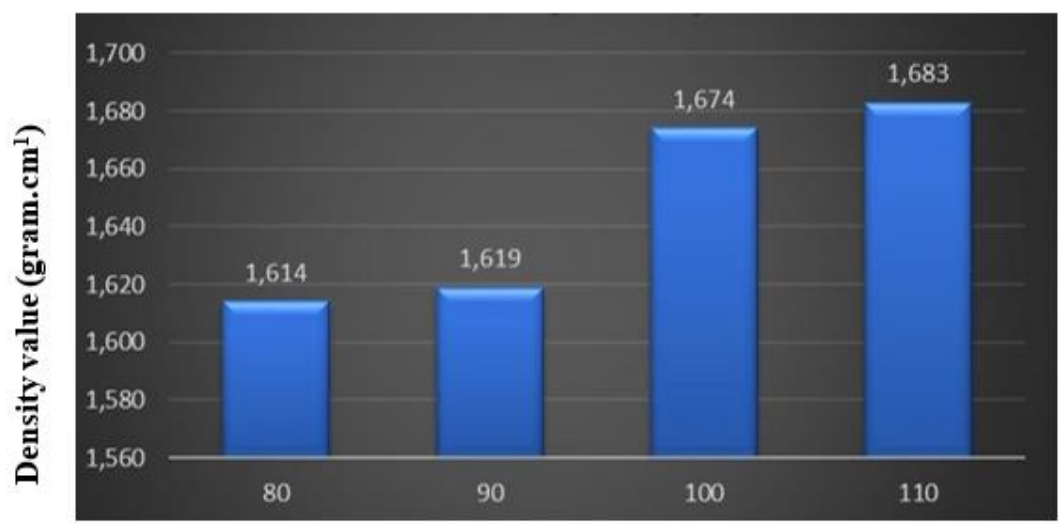

Milling time duration (minutes)

FIGURE 2. The relation between the variation of milling time and the density value of Glass Ionomer Cement

The graph of the measurement of the density value indicated that the density value of dental cement was increasing as the increasing milling time variation, since the longer the variation in milling time, the more homogeneous the mixture of dental cement. From the results calculation, the highest density value was obtained at the variation of the milling time 110 minutes with a density value of $1.683 \pm 0.004 \mathrm{gram} / \mathrm{cm}^{3}$, while the lowest density value was obtained at the milling time variation of 80 minutes with a density value of $1.614 \pm 0.004$ gram $/ \mathrm{cm}^{3}$. The density value obtained from the calculation result was different from the literature, namely in tooth enamel of $2.96 \mathrm{grams} / \mathrm{cm}^{3}$.

\section{Compressive Test Strength Result}

The measurement of the compressive strength test was executed using the loading method, such as by applying a load to the sample until the sample was brittle. This method intended to determine the compressive strength of the sample when receiving a load. The data obtained were the sample diameter and the maximum force required to compress the sample. The compressive strength value of each sample then could be calculated. The results of the compressive strength test was represented in Figure 3 which was illustrated by a graph of the relation between milling time variations and the compressive strength of the sample.

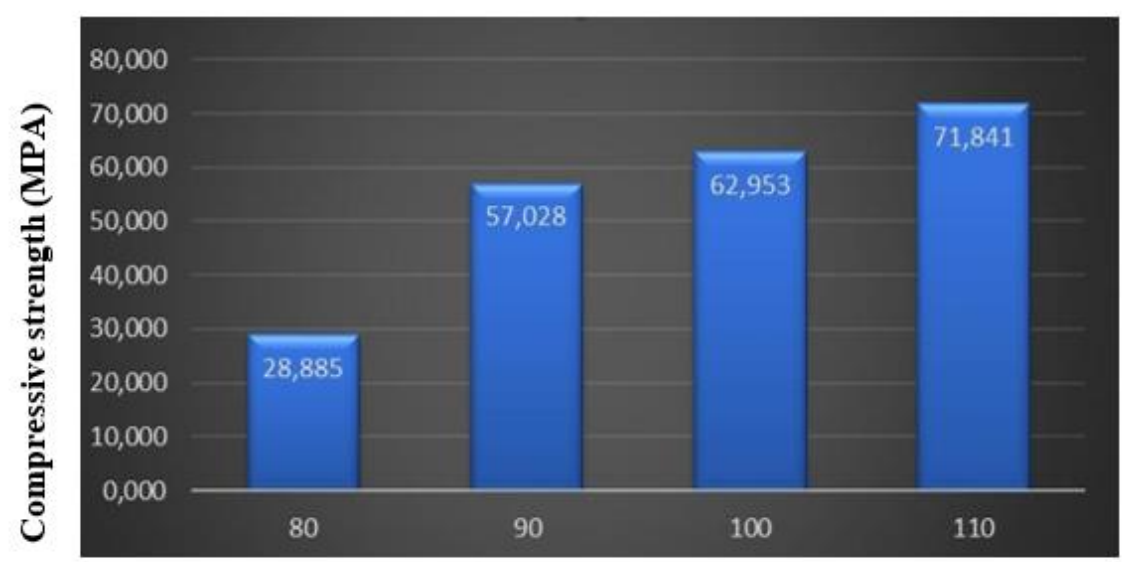

Milling time duration (minutes)

FIGURE 3. The Relation Between Milling Time Variations and The Compressive Strength of The Sample

In line with Figure 3, the compressive strength value increases as the increasing of grinding process time. The longer the grinding time, the more homogeneous the mixture of ingredients which would affect the process of making 
dental cement. The longer the milling time, it would reduce the brittleness of the dental cement. Figure 4.2 shows that the compressive strength of dental cement gave the highest value in sample D with a variation of the grinding time for 110 minutes, which was $71,841 \pm 0.445 \mathrm{MPa}$. The compressive strength value obtained did not meet the desired value in the literature, such as the tooth enamel of $94-450 \mathrm{MPa}$.

\section{Hardness Test Result}

Measurement of hardness values was done using the Microvickers Hardness method. Hardness test intended to determine the ability of a sample to accept a load. The measurement of the level of hardness was carried out at three different points, namely the right side, the middle side, and the left side of the sample. The load when data collection is $0.2 \mathrm{kgf}$ or $1.96 \mathrm{~N}(1 \mathrm{kgf}=9.8 \mathrm{~N})$. The data obtained of the vickers hardness test were the sample hardness value (VHN), diagonal 1 and diagonal 2. From the three points that had been given a load, the average VHN value was obtained. The results of the calculation of the hardness value were represented in Figure 4 which was illustrated by a graph of the relation between the variation of the milling time and the hardness value.

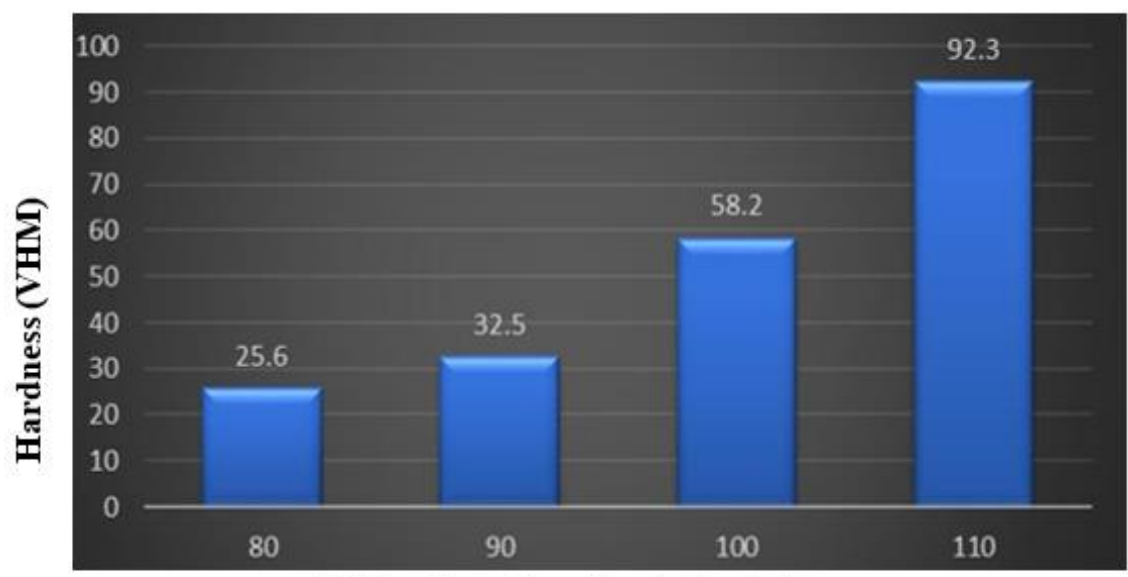

Milling time duration (minutes)

FIGURE 4. The Relation Between Milling Time Variations and The Compressive Strength of The Sample

Based on Figure 4, the hardness value was in line with the compressive strength value. The results of the test stated that the hardness value increases with increasing milling time. The longer the milling time, the more homogeneous the mixture of materials and causing the hardness to increase. From the results of the study, the highest hardness value was obtained in the variation of milling time of 110 minutes with a hardness value of $92.3 \pm 7.5 \mathrm{VHN}$, while the lowest hardness value was obtained at the variation of milling time of 80 minutes with a hardness value of $25.6 \pm 0.9 \mathrm{VHN}$. The hardness value obtained was different from the literature, such as the tooth enamel was $274.8 \mathrm{VHN}$.

In line with the results in this study, it can be suggested that in further research it is necessary to carry out the milling process using a ball mill in order to obtain a smaller particle size in order to increase the surface area of the sample and the reaction can be more effective, moreover adding other additives which are according to the composition for dental fillings.

\section{CONCLUSION}

1. Based on the research, it is concluded that the additional milling time affects the yield of GIC, the longer the milling time will increase the density, compressive strength and hardness of GIC dental cement.

2. Milling time greatly affects the homogenization of a material. In accordance with this research, the optimum milling time to obtain the GIC characteristics with the addition of the best PVME-MA liquid was 110 minutes.

\section{REFERENCE}

1. Anita, S. 2015. Pengaruh Variasi Waktu Milling Terhadap Karakteristik Semen Gigi Glass Ionomer Cement (GIC). Skripsi Program S-1 Fisika Departemen Fisika. Fakultas Sains dan Teknologi Universitas Airlangga: Surabaya

2. Palma,et al. 2002. Microhardness of Esthetic Restorative Materials at Different deppths. Material Research.

3. Riset Kesehatan Dasar (Riskesdas), 2013. Badan Penelitian dan Pengembangan Kesehatan. Jakarta: Departemen Kesehatan Republik Indonesia. 
ISSN 2745-3502

Volume 1 No. 2 - Desember 2020

Indonesian Applied Physics Letters

4. Sakaguchi, R.L. and Powers J.M., 2012, Restorative Dental Material, Thirteenth edition. Elsevier : United States.

5. Widana, Gede Agus Beni. 2012. Sintesis Dan Karakterisasi Semen Gelas Ionomer Sistem $\mathrm{SiO}_{2}-\mathrm{Al}_{2} \mathrm{O}_{3}-\mathrm{CaF}_{2}$. Tesis Program S-2 Kimia Institusi Teknologi Sepuluh Nopember: Surabaya. 